\title{
Student help seeking from pastoral care in UK high schools: a qualitative study
}

\author{
Sarah Kendal, Philip Keeley \& Peter Callery \\ University of Manchester, School of Nursing Midwifery and Social Work, M13 9PL, UK. E-mail: sarah.kendal@manchester.ac.uk
}

\begin{abstract}
Background: Little is known about high school students' perceptions of school-based pastoral support. This study aimed to explore this in the context of a high school-based emotional support project. Methods: Qualitative interviews explored perspectives on help seeking of students $(N=23)$ and staff $(N=27)$ in three UK high schools where a pastoral project was introduced. Data were analysed thematically. Results: Student peer groups perceived help seeking as a sign of weakness. However, students valued learning skills in managing emotions and friendships. Staff expressed concerns about students' ability to help seek proactively, and highlighted organisational influences on pastoral support. Conclusions: Increasing student control over the process, and involving trusted staff, could encourage help seeking in high school. It is possible to access the views of students who do not help seek, to improve understanding of help-seeking behaviour.
\end{abstract}

\section{Key Practitioner Message}

- Young people's mental health is a global concern

- Emotional support provided in schools can help to address this problem, but it often relies on the young person actively seeking help

- Peer group perceptions may discourage young people from seeking emotional support within a school setting

- The young people in this study made help-seeking decisions after judging potential risks and benefits as they saw them

- Help seeking in school could be encouraged by involving staff whom students perceive as trustworthy; allowing students control over information sharing; and developing a school culture in which help seeking is seen as a positive action.

Keywords: Help seeking; qualitative; pastoral; school; student; emotional

\section{Background}

Mental health is a pressing public health concern. The UK National Survey of Children and Young People's Mental Health estimated around $10 \%-13 \%$ of $11-$ 16 year olds have a mental disorder Meltzer, Gatward, Goodman, \& Ford, 2003), but the real figure is likely to be much higher as the problem is often hidden (Macdonald, 2000). Emotional disorders are associated with increased likelihood of developing behaviours including self-harm, alcohol consumption, drug use, regular smoking, absences and exclusions from school and difficulties with social relationships (Hawton et al., 2012; Meltzer, Gatward, Goodman, \& Ford, 2000; Meltzer et al., 2003; Ystgaard et al., 2009). Early intervention to promote emotional well-being in young people could be a helpful strategy (Department of Health, 2011; World Health Organization, 2013; World Health Organization Europe, 2005).

Pastoral care is one of the criteria against which the quality of UK schools is measured (Office for Standards in Education, Children's Services and Skills, 2012). Although there does not appear to be a widely accepted UK definition (Calvert, 2009), it has been described as: the term used in education in the United Kingdom to describe the structures, practices and approaches to support the welfare, well-being and development of children and young people' (Calvert, 2009: 267). In respect of students' emotional well-being, it is common practice to deliver emotional support programmes to whole schools, cohorts, or to students identified as vulnerable (Department of Education, 2011). The evidence from reviews of emotional well-being promotion strategies in school supports curriculum-based programmes (Durlak, Weissberg, Dymnicki, Taylor, \& Schellinger, 2011; Greenberg et al., 2003; Weare \& Nind, 2010). However, such large programmes may involve curriculum changes and specialist input, and they can encounter implementation difficulties, or be time limited (Lendrum, Humphrey, Kalambouka, \& Wigelsworth, 2009; Sawyer et al., 2009). Schools can also develop their own models of pastoral provision outside the curriculum (Department of Education, 2011; Vostanis et al., 2012). In UK high schools, much of the routine, day to day, pastoral support for individual students is provided by form tutors and other teaching staff (Department for Education, 2012). The support they receive in this role varies between schools (Fox \& Butler, 2009; Shaper \& Streatfield, 2012; Vostanis et al., 2012) and routine pastoral care in schools has received little attention in the literature. 
Some problems, such as disruptive behaviour and underachievement, cause concern to parents or teachers (Department of Education, 2011; Vostanis et al., 2012). However, less visible problems may only be identified by young people seeking help. According to the health literature, young people may avoid asking for help if they lack trust in the health practitioner's skill or judgement, or if they feel unwelcome or embarrassed (Freedenthal \& Stiffman, 2007; Ginsburg, Forke, Cnaan, \& Slap, 2002; Gleeson, Robinson, \& Neal, 2002). Little attention has been paid to how young people feel about accessing emotional support in school. Potentially, these barriers may also apply to help seeking in a school setting.

The aim of this study was to examine barriers and facilitators to help seeking in a pastoral care project in three UK high schools.

\section{Study setting}

A project to enhance pastoral care in high schools ('the Project') was developed from a consultation process with students in three urban UK high schools (A, B and C). It was subsequently delivered in those schools from November to July of a single school year (see Kendal, Callery, \& Keeley, 2011; Kendal, Keeley, \& Callery, 2011 for detailed reports on development and evaluation). School A had 1200 students, School B had 1700 students and School C had 600 students. Two schools were coeducational and one was a girls' school.

The aim was to provide structured, low-intensity support for students who self-referred with anxiety, low mood and related difficulties, using the supported selfhelp model (Lovell, Bee, Richards, \& Kendal, 2006). In the United Kingdom, high school students are either in Key Stage 3 (KS3; 11-14 years) or Key Stage 4 (KS4; 1416 years). The project was delivered by teaching assistants and pastoral staff already based in the schools, who received brief training and weekly supervision specifically for the role of Project Worker. Information about student contact was not shared with anyone outside the Project team, except in the event of concerns about safety. This was counter to the usual information sharing practice in schools. Brief details of student contacts with the project were recorded by Project Workers on anonymised forms that were subsequently made available for analysis.

During the project, students mainly presented with problems of relationships (making and keeping friends, coping with bullies, getting on with teachers, pleasing parents); schoolwork; and anger. Other difficulties were around self-esteem, transition, panic, grief, sexuality and self-harm. Most of these young people described linked difficulties, such as a combination of anger and friendship problems.

However, although young people as well as staff gave positive feedback, relatively few had used the project: 12 from KS3, eight from KS4 and oneSixth form student (16-18 years), representing $0.6 \%$ of students compared with an estimated $10 \%-13 \%$ prevalence of mental health problems in this age group in the United Kingdom, although the rate in these schools was not known. There is limited evidence concerning help-seeking rates for emotional support in high school. A KS3 peer antibullying scheme in a London girls' school reported uptake by $30.7 \%$ of younger students in KS3 and $10.7 \%$ of older students in KS3 (Houlston \& Smith, 2009). In the context of sexual health, another potentially sensitive issue, an HPV (Human papillomavirus) vaccination programme delivered in high schools in Greater Manchester reported wide ranging uptake of 33.6\%-92.0\% (Brabin et al., 2011). These disparate findings indicate the importance of understanding the influences on young people's decisions about accessing well-being support in school.

\section{Methods}

\section{Methodological approach}

The design was conceptually located in the theoretical and modelling phases of the complex interventions framework (Campbell et al., 2007) which emphasises the relevance of context to study design. A qualitative design was appropriate to explore the views of young people and a practical approach was needed to recruit a group who were potentially hard to reach, that is, individuals who had not been in contact with the Project. The approach was informed by principles of flexibility in response to social context and an analytic aim of interpreting the meaning and significance of data (Popay, Rogers, \& Williams, 1998).

\section{Recruitment and sampling}

The aim was to explore perspectives on the Project by consulting students who had, and students who had not sought help, plus members of school staff. A purposive sample was formed comprising students and staff from each of the three schools, including KS3 and KS4 students and staff in a range of roles: teaching assistants, pastoral staff, qualified teachers and managers. Pastoral staff were actively involved in recruitment and made use of their personal contacts within the schools to assemble the sample of students. SK, supported by pastoral staff, recruited staff through a combination of verbal and written invitation.

Data collection. Students and staff participated in qualitative interviews conducted by SK which incorporated open questions and prompts about specific components of the intervention relevant to the research aims (Kendal, Callery et al., 2011). The main messages from interviewees were confirmed by them at the end of each interview. Table 1 illustrates a selection of interview topics.

Ethical issues. The University of Manchester ethics committee approved the study (TPCS/ethics/06166). A

Table 1. Sample topic guide (students)

- What do you know about the Project?

- Can you remember how you heard about it?

-What did you think of the support you get in school at the moment?

- (If used Project) What kind of support did you get?

- (If did not use Project) Support: what kind is useful? (e.g.

Advice, coping, other)

- How important is confidentiality - school friends, staff, home?

- Could you say a bit about the problems that young people have?

-What do young people like you do about any problems they have?

- What could encourage/discourage someone from using this Project?

- Can you suggest anything to improve this Project? 
safeguarding protocol was agreed with each school to support any participant who might require it, following the interview. Stringent efforts were made to protect the confidentiality of all participants. Therefore, demographic data were limited to school, age range or school role and gender. Participant identity has been concealed in this study.

Analysis. Data were organised using the framework method (Ritchie, Spencer, \& O'Connor, 2007) and a thematic analysis was developed by the method of constant comparison and responsiveness to emerging insights. Transcribed interview data were entered into an NVIVO 7 database for data analysis. They were grouped by school, student or staff, and academic Key Stage or staff role. The first level of coding grouped the data into categories that matched the topic guide. As familiarity with the data grew, insights developed and these categories were exploded, merged and redefined, becoming increasingly conceptual. Areas of disagreement were discussed and resolved within the research team. From this process of grouping, reading, sorting, reflection, consultation and review, clear themes were identified.

Rigour was enhanced through the following strategies, based on standards setout by Popay et al. (1998): The authors met regularly throughout the analysis period to discuss emerging findings and check their consistency across the data. Links with the raw data were maintained via the software, which created an audit trail and allowed the developing coding framework to be repeatedly tested against the interview transcripts. The project had an advisory group that included young people (1516 years) from other schools who checked anonymised samples of coded interview data, and either verified or challenged the analysis and interpretation. They had contemporary knowledge about the experiences of being in high school and they were able to advise on how to interpret idiomatic language that was used by student interviewees. SK had prolonged engagement with the school over 18 months during the planning stages, Project delivery and data collection and analysis and therefore had a deep understanding of the social context to aid interpretation of the data.

Throughout the study, SK kept a reflexive journal, which helped to clarify researcher influences on the study. These included SK's insights into the social environment of the school. In addition, the design and conduct of the study was influenced by the authors' backgrounds in mental health nursing (SK and PK) and children's nursing (PC).

Table 2. Interview sample

\begin{tabular}{|c|c|c|c|c|c|}
\hline School & Interviewee & $\begin{array}{l}\text { Used/ } \\
\text { delivered } \\
\text { project }\end{array}$ & $\begin{array}{l}\text { Did not use/ } \\
\text { deliver } \\
\text { project }\end{array}$ & $\begin{array}{c}\text { Total } \\
\text { students }\end{array}$ & $\begin{array}{l}\text { Total } \\
\text { staff }\end{array}$ \\
\hline \multirow[t]{2}{*}{ A } & Students & 2 & 8 & 10 & \\
\hline & Staff & 2 & 9 & & 11 \\
\hline \multirow[t]{2}{*}{ B } & Students & 3 & 1 & 4 & \\
\hline & Staff & 3 & 4 & & 7 \\
\hline \multirow[t]{2}{*}{ C } & Students & 4 & 5 & 9 & \\
\hline & Staff & 3 & 6 & & 9 \\
\hline Totals & & 17 & 33 & 23 & 27 \\
\hline All & & & & & 50 \\
\hline
\end{tabular}

\section{Results}

\section{Interview sample}

The interview sample comprised 23 students ( 8 male, 15 female; 15 from KS3, 8 from KS4); and 27 staff: (7 male, 20 female; 17 with predominantly pastoral roles including eight who had delivered the Project, 10 with predominantly teaching or management roles). Table 2 summarises the sample.

Nine of the student interviewees had used the project. Of these, eight said that they had benefitted from it. The quotation below is representative.

"I've learnt how to cope with issues, and like problems and everything in a whole, you know, different way" (Female, KS3, School B).

The ninth said that it had not helped at all. No harmful effects from the project were observed or reported during the study.

\section{Interview findings}

The qualitative interview style encouraged interviewees to explain their personal perspectives on issues around help seeking for emotional support. There was striking consistency between reports from all the students, suggesting common concerns and values. In contrast, staff highlighted differences between the cultural norms of each school. Students reported a range of internal, personal processes that formed barriers to using the Project, whereas staff tended to focus on organisational issues. Two main themes were identified: students' fear of emotional exposure in school; and the impact of the organisational context.

\section{Students' fear of emotional exposure in school}

Worries about looking vulnerable seemed to pervade social behaviour and patterns of emotional management in students. Students reported that the efforts they made to present a self-image that would attract the friendship or admiration of their peers. The school context affected social rules, interactions and perceived threats to social and emotional well-being including loss of control over personal information.

Impact of peer group norms. The fact of being on the school premises appeared to encourage students to conform to peer group etiquette, a distinct set of social rules that required them to hide any vulnerability from a potentially hostile peer group. As one student explained,

"Everybody kind of puts a mask on, as soon as they come in through the gate, and they bottle up all their emotions, and all this, and the second they get home, they take the mask off, because nobody here is the same as they are when you just see them by themselves." (Female KS3, School B)
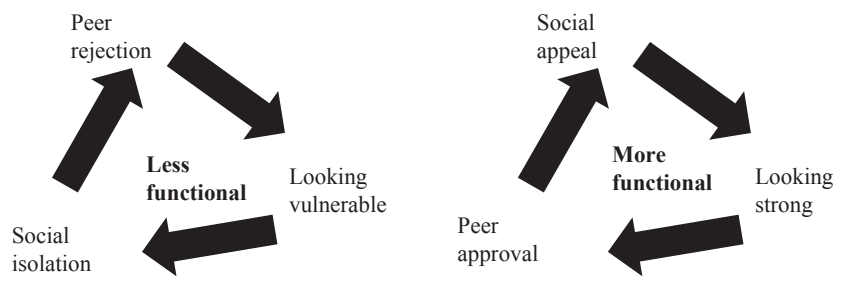

Figure 1. Relationship between emotional exposure and risk 
One effect of these rules seemed to be that students were reluctant to ask for emotional support in school. Admitting a need for help, or being known to have asked for help, could create an unattractive impression of weakness that might alienate potential allies. A tough public image was seen as a major asset to making and keeping friends (see Figure 1). This might involve displays of aggression:

"They're all in a gang at school, they go all around, they don't bully you if it's just one on one... [only] if there's a crowd." (Female KS3, School C)

There seemed to be a general agreement between the young people that it was undesirable and potentially unsafe, both physically and emotionally, to be socially isolated.

Weighing up the risks. Disclosure in school risked showing other people a vulnerability or weakness. It was consistent with peer group values that individuals made exacting analyses of the potential risks and benefits of help seeking. On one hand, there was the possibility of resolving or mitigating a problem. On the other, there was a clutch of risks that had to be considered, including feeling inadequate for needing help, the possibility that other people (especially peers and class teachers) might find out, and a judgement of one's ability to cope if the worst - emotional exposure should happen.

A recurring message from students was the extent to which worries about exposure could impact on help seeking:

"If you tell teachers or parents about being bullied] they might just like tell everyone and then...just make you get more bullied." (Male, KS3, School A)

"There's nothing worse than trusting someone... and then it going round the whole school...Because you have to think, will they go and phone the other friend and tell them, will they blurt it out when they are in an argument?" (Female, KS3, School B)

"I think teachers can sometimes be say a little bit nosy, so sometimes if you are upset you have to kind of hide it...[or] everything gets blown out of proportion." (Female, KS3, School B)

Many staff were sensitive to the risks of emotional exposure that students dealt with at school. Using an example from a peer-mentoring project that had previously run in the school, one member of pastoral staff described how serious exposure could be:

"One of our pupils (peer-mentored) another girl, and actually it sort of came out about her, you know, being gay, and her life was virtually destroyed for months, because of how the other person used it." (Staff, School C)

Some students saw the potential benefits as greater than the risks:

"Um I just said, I just give it a shot, nothing can happen, nobody going to kill me for [using the Project]." (Male, KS3, School A).

This sense of resilience to unwelcome exposure was not expressed by many of the young people interviewed. Those students who did communicate resilience tended to have more anecdotes about having survived social problems in school. Older students could have the additional problem of shame.

"The feeling that, oh my God I'm stupid...being ashamed of relying on someone else to help you...it makes them feel a bit weak." (Male, KS4, School A).

Lack of confidentiality. Despite a sensitive attitude among many staff, there was consensus between the students that they should be wary of trusting staff, particularly teachers, with personal information. Students tended to appreciate that teachers had to follow protocols, but there was also a widely held belief that they enjoyed gossiping with each other:

"Some [teachers] have big mouths." (Female, KS3, School C).

"Some like teachers in the school, not all of them, but some, would just go and tell all the other teachers when they're in the staffroom." (Male, KS4, School A).

Uncertainty about confidentiality seemed to generate a reluctance to access any support in school, unless the individual was willing to cope with the risk of exposure or believed they could trust the person offering help. The Project Workers, who were not qualified teachers, were seen as trustworthy and good people to approach for emotional support:

"With it being [pastoral staff], you know you can trust them with pretty much everything, so that helps a lot" (Male, KS4, School A).

\section{Impact of the organisational context}

A striking finding from the interviews with staff was that school A had blocked the advertising for the project. Some staff explained that since becoming involved with the project, School A had acquired a new leadership team that was heavily invested in image promotion with school visitors and the local community. As one explained, this was part of a strategy to maintain the school's popularity:

"A school which suddenly sort of starts to appear to have lots of problems is likely to start to sort of lose people applying to it" (Staff, School A)

This suggests that the project no longer fitted with the school ethos and was not supported by senior management. As access was through self-referral, the lack of advertising was an effective barrier. Only two students from this school used the project, although many others supported the idea of it, once it had been explained to them at the start of the interview:

"If [one of my friends] knew about that project they might go to it" (Male, KS3, School A).

Overall, the Project Workers expressed a need for both moral and practical support for the role. This seemed to depend on having clear championing by the school leadership. Managers in School C, encouraged the staff to participate in the Project, and allocate protected time for this activity. This quotation from School $\mathrm{C}$ reflects the enthusiasm of the school management team for the Project.

"There was this great interest from the [teaching assistants] ...we got, was it 10 or something like that on board... so that was a great success" (Staff, School C). 
Staff in Schools A and B did not have protected time, and this caused them some difficulties:

"We're there basically to support the students, and [the Project] is taking time off the students"; "You almost feel like, sort of, guilty" (Staff, School B).

Project workers struggled to find time to complete the project paperwork, which included consent forms and measures in addition to contact records. Some reported that they simply could not manage it.

All the Project workers added other referral routes to the self-referral pathway indicated. This was in response to staff concerns that self-referral was inaccessible to the less able students.

"It had to be more flexible... we had to change it... a lot of kids these days... they haven't got them skills, to actually [self]refer, you know" (Staff, School A).

However, most students who were interviewed explained that the self-referral route was the main trigger for seeking help because it promised the privacy they wanted.

"It was okay because I just told my friends I had to see someone and they did not know what I was going for" (Female, KS4, School B).

\section{Discussion}

Students' help seeking was driven by their sense of who they were, their place in their social groups and how they wished to be perceived in those groups. According to the data, a person perceived as weak is less likely to attract friends, which in turn causes social isolation and further vulnerability. Conversely, a person perceived as tough attracts friends and shores up social support, hence becoming increasingly protected within the peer group. Two self-perpetuating cycles were identified in the data (see Figure 1). In the first, social isolation, visible vulnerability and peer rejection maintain each other. In the second, social appeal, the appearance of strength and peer approval reinforce each other.

Young people who had used the Project saw help seeking as a positive act, and it is possible that it was easier for individuals who were less concerned about their social status or else felt sufficiently secure to go against the norms for social behaviour. Some developmental theory suggests that a young person's selfconcept and behaviour can be constantly shifting and changing in response to changing social situations (Coleman, 2011; Shavelson, Hubner, \& Stanton, 1976). This perspective may help explain the strong influence of school on the help-seeking decisions of the young people in the study. Help seeking in school could be encouraged by emphasising potential gains within the peer group through skills in making and keeping friends, dealing with conflict and maintaining self-esteem.

A further, tentative suggestion is that it may be possible to encourage help seeking within a school setting by influencing peer values, perceptions of vulnerability, or social relationships. However, School A leadership was concerned about the impact of the Project on the school's reputation. A school culture that does not support help seeking may discourage students from accessing emo- tional support. This reasoning can be seen in the destigmatising components of many health promotion campaigns (Stangl and World 2010). The impact of context on young people's help seeking has been reported widely in the health literature (Brabin et al., 2011; Gleeson et al., 2002).

Social cognitive theory proposes that social norms are one of several influences on health behaviour (Conner \& Norman, 1996). It may be that for the young people in this study, social norms were the primary influence on help seeking from the Project. This knowledge could help to adapt theories developed for adults, and make them more relevant to young people.

\section{Strengths and limitations of the study}

The study produced new insights into how young people may feel about seeking emotional support in school which have potential to inform pastoral provision in high school, and the design of exploratory research within high school settings.

The design and scope of the study has implications for interpretation of the findings. The exploratory aims of this research required a qualitative design, in which researcher influence is acknowledged as part of the process (Mays \& Pope, 2000). The trustworthiness and rigour of qualitative research can be demonstrated via key criteria of credibility, transferability, dependability and confirmability (Guba, 1981; Shenton, 2004). This study employed a range of techniques, including: the use of established qualitative methods; reflexivity and detailed description; SK's familiarity with the schools; a wide range of informants including interviewees with no involvement in the project; asking open questions in interviews; checking data with interviewees; involving young people in data analysis; frequent debriefing sessions by the supervising team (PC and $\mathrm{PK})$; and detailed reporting of methods.

Recruitment and data collection were shaped by what was acceptable and feasible within the school setting (Milnes \& Kendal, 2012). The methods were feasible within the school context and enabled collection of data about potentially sensitive topics, although it is possible that perspectives on some issues may not have been accessed. The study was developed and managed by a small research team with clinical interests, and their potential influence on the findings must be acknowledged. The recruitment strategy had to fit the context, in which opportunities for interviewing were defined by the schools. There were more staff than students in the sample, which reflects difficulties in recruiting students. Given the students' concerns about privacy and confidentiality, it is unsurprising that fewer students than staff were willing to be interviewed.

\section{Conclusion}

The study findings suggest that young people may be reluctant to access help in schools, but also highlighted strategies that schools might consider adopting, including: involving staff whom students trust (potentially from non-teaching roles); respecting students' privacy; enabling students to make choices about help seeking and information sharing; and encouraging a supportive social environment. 
Further research could develop methods of consulting with young people on the design of pastoral support in school which is appropriate for their needs. The findings from this study suggest that pastoral support in school is enhanced by involving trusted staff, and finding ways of enabling students who access support to protect their public image.

At an organisational level it may be helpful to explore ways of working with school management, to identify and reduce the stigma associated with emotional difficulties.

Researchers and practitioners attempting to develop pastoral support in schools could invest time in understanding the social norms and value system of each school setting.

Finally, future research could address whether positive school cultures would encourage students to access and engage in available support.

\section{Acknowledgments}

This study was part of a doctoral thesis funded by the University of Manchester School of Nursing, Midwifery and Social Work.

The authors have declared that there are no competing or potential conflicts of interest.

\section{References}

Brabin, L., Stretch, R., Roberts, S.A., Elton, P., Baxter, D., \& Mccann, R. (2011). The school nurse, the school and HPV vaccination: A qualitative study of factors affecting HPV vaccine uptake. Vaccine, 29, 3192-3196.

Calvert, M. (2009). From 'pastoral care' to 'care': Meanings and practices. Pastoral Care in Education, 27, 267-277.

Campbell, N.C., Murray, E., Darbyshire, J., Emery, J., Farmer, A., Griffiths, F., ... \& Kinmonth, A.L. (2007). Designing and evaluating complex interventions to improve health care. $B M J, 334,455-459$.

Coleman, J. (2011). The nature of adolescence. Sussex: Routledge.

Conner, M., \& Norman, P. (1996). Predicting health behaviour: A social cognition approach. In M. Conner, P. Norman (Eds.), Predicting health behaviour. Research and Practice with Social Cognition Models (pp. 1-27). Ballmore: Buckingham.

Department of Education. (2011). Me and my school: Findings from the national evaluation of targeted mental health in schools 2008-2011. Research Report DFE-RR177. (Department for Education). Crown copyright, Available from: https:// www.education.gov.uk/publications/standard/publication detail/page1/dfe-pr177\#downloadedreports

Department for Education. (2012). Pastoral Care. Available from: http://www.education.gov.uk/schools/pupilsupport/ pastoralcare [last accessed 01 December 2012].

Department of Health. (2011). No health without mental health. London: Department of Health.

Durlak, J.A., Weissberg, R.P., Dymnicki, A.B., Taylor, R.D., \& Schellinger, K.B. (2011). The impact of enhancing students' social and emotional learning: A meta-analysis of school-based universal interventions. Child Development, 82, 405-432.

Fox, C.L., \& Butler, I. (2009). Evaluating the effectiveness of a school-based counselling service in the UK. British Journal of Guidance and Counselling, 37, 96-106.

Freedenthal, S., \& Stiffman, A.R. (2007). "They might think i was crazy": Young American Indians' reasons for not seeking help when suicidal. Journal of Adolescent Research, 22, 58-77.

Ginsburg, K.R., Forke, C.M., Cnaan, A., \& Slap, G.B. (2002). Important health provider characteristics: The perspective of urban ninth graders. Journal of Developmental and Behavioral Pediatrics, 23, 237-243.
Gleeson, C., Robinson, M., \& Neal, R. (2002). A review of teenagers' perceived needs and access to primary health care: Implications for health services. Primary Health Care Research and Development, 3, 184-193.

Greenberg, M.T., Weissberg, R.P., O'Brien, M.U., Zins, J.E., Fredericks, L., Resnik, H., \& Elias, M.J. (2003). Enhancing school-based prevention and youth development through coordinated social, emotional, and academic learning. American Psychologist, 58, 466-474.

Guba, E.G. (1981). Criteria for assessing the trustworthiness of naturalistic inquiries. Educational Communication and Technology Journal, 29, 75-91.

Hawton, K., Bergen, H., Kapur, N., Cooper, J., Steeg, S., Ness, J., \& Waters, K. (2012). Repetition of self-harm and suicide following self-harm in children and adolescents: Findings from the Multicentre Study of Self-harm in England. Journal of Child Psychology and Psychiatry, 53, 1212-1219.

Houlston, C., \& Smith, P.K. (2009). The impact of a peer counselling scheme to address bullying in an all-girl London secondary school: A short-term longitudinal study. British Journal of Educational Psychology, 79, 69-86.

Kendal, S., Callery, P., \& Keeley, P. (2011). Evaluation of the feasibility and acceptability of an emotional wellbeing intervention for high school students: A qualitative study. Child and Adolescent Mental Health, 16, 193-200.

Kendal, S., Keeley, P., \& Callery, P. (2011). Young people's preferences for emotional wellbeing support in high school- a focus group study. Journal of Child and Adolescent Psychiatric Nursing, 24, 245-253.

Lendrum, A., Humphrey, N., Kalambouka, A., \& Wigelsworth, M. (2009). Implementing primary Social and Emotional Aspects of Learning (SEAL) small group interventions: Recommendations for practitioners. Emotional and Behavioural Difficulties, 14, 229-238.

Lovell, K., Bee, P., Richards, D., \& Kendal, S. (2006). Self-help for common mental health problems: Evaluating service provision in an urban primary care setting. Primary Health Care Research and Development, 7, 211-220.

Macdonald, W. (2000). Child and adolescent mental health and primary care: Current status and future directions. Current Opinion in Psychiatry, 13, 369-373.

Mays, N., \& Pope, C. (2000). Quality in qualitative health research. In N. Mays \& C. Pope (Eds.), Qualitative research in health care chapter 8(pp. 89-101). Oxford: BMJ Books.

Meltzer, H., Gatward, R., Goodman, R., \& Ford, T. (2000). The mental health of children and adolescents in Great Britain: The report of a survey carried out in 1999 by Social Survey Division of the Office for National Statistics on behalf of the Department of Health, the Scottish Health Executive and the National Assembly for Wales. HMSO, London.

Meltzer, H., Gatward, R., Goodman, R., \& Ford, T. (2003). Mental health of children and adolescents in Great Britain. Inter national Review of Psychiatry, 15, 185-187.

Milnes, L., \& Kendal, S. (2012). Ethical challenges of conducting health research in UK high school settings. British Journal of Nursing, 21, 294-298.

Office for Standards in Education, Children's Services and Skills (OFSTED). (2012). School inspection handbook: Handbook for inspecting schools in England under section 5 of the Education Act 2005 (as amended) from September 2012. OFSTED/UK Government: Manchester.

Popay, J., Rogers, A., \& Williams, G. (1998). Rationale and standards for the systematic review of qualitative literature in health services research. Qualitative Health Research, 8, 341-351.

Ritchie, J., Spencer, L., \& O'Connor, W. (2007). Carrying out qualitative analysis, Chapter 9. In J. Ritchie \& J. Lewis (Eds.), Qualitative research practice: A guide for social science students and researchers (pp. 219-262). London: Sage.

Sawyer, M.G., Pfeiffer, S., Spence, S.H., Bond, L., Greatz, B., Kay, D., . . \& Sheffield, J. (2009). School-based prevention of depression: A randomised controlled study of the beyondblue schools research initiative. Journal of Child Psychology and Psychiatry, 51, 199-209. 
Shaper, S., \& Streatfield, D. (2012). Invisible care? The role of librarians in caring for the 'whole pupil' in secondary schools. Pastoral Care in Education: An International Journal of Personal, Social and Emotional Development, 30, 65-75.

Shavelson, R., Hubner, J., \& Stanton, G. (1976). Self-concept: Validation of construct interpretations. Review of Educa tional Research, 46, 407-441.

Shenton, A.K. (2004). Strategies for ensuring trustworthiness in qualitative research projects. Education for Information, 22, 63-75.

Stangl, A. \& World Bank. (2010). Tackling HIV-related stigma and discrimination in South Asia. Washington, D.C.: World Bank.

Vostanis, P., O’Reilly, M., Taylor, E., Day, C., Street, C., \& Wolpert, M. (2012). What can education teach child mental health services? Practitioners' perceptions of training and joint working. Educational and Behavioural Difficulties, 17, 109-124.

Weare, K., \& Nind, M. (2010). Identifying evidence-based work on mental health promotion in schools in Europe: An interim report on the DataPrev project. Advances in School Mental Health Promotion, 3, 36-44.

World Health Organization. (2013) The school health component of the Mega Country Health Promotion Network. Available from: http://www.who.int/school_youth_health/mega/ en/ [last accessed 7 April 2013].

World Health Organization Europe. (2005) Mental health of children and adolescents (WHO European Ministerial Conference on Mental Health: Briefing document. Helsinki, Finland. Available from: http://www.euro.who.int/document/MNH/ ebrief14.pdf [last accessed 25 November 2008].

Ystgaard, M., Arensman, E., Hawton, K., Madge, N., Van Heeringen, K., Hewitt, A., .. . \& Fekete, S. (2009). Deliberate selfharm in adolescents: Comparison between those who receive help following self-harm and those who do not. Journal of Adolescence, 32, 875-891.

Accepted for publication: 7 March 2013 